\title{
Analysis of deformation characteristics and stability mechanisms of typical landslide mass based on the field monitoring in the Three Gorges Reservoir, China
}

\author{
Yonggang Zhang ${ }^{1}$, Shuyun Zhu ${ }^{1}$, , Weiqiang Zhang ${ }^{1}$ and Hui Liu $^{2}$ \\ ${ }^{1}$ School of Resources and Geosciences, China University of Mining and Technology, Xuzhou 221116, China. \\ ${ }^{2}$ School of Highway, Chang'an University, Xi'an 710064, China. \\ *Corresponding author. e-mail: shyzhuqiao@163.com
}

MS received 4 December 2017; revised 30 January 2018; accepted 5 April 2018; published online 1 December 2018

Based on a large number of data including GPS monitoring of surface deformation and inclinometer monitoring of internal deformation over 7 years, we find that the displacement of a typical landslide mass has the stepped evolution characteristics as: the variation of the reservoir water level under the different years and months in the Three Gorges Reservoir and the deformation of landslide mass surges in the flood season. On the contrary, the deformation of landslide mass slows down in the non-flood season. Especially, in 2007, 2009 and 2011, the fluctuation of the surface monitoring displacement is more intense than that in the other years. In addition, the whole landslide mass has a characteristic of the trial-type sliding. The surface displacement is greater than the internal displacement. Based on that, deformation characteristics, stability mechanisms and the influencing factors of landslide mass are studied deeply. The results show that the drawdown of the water level of the Three Gorges Reservoir region is the main controlling factor of the deformation of the landslide mass. The results of the study have a significant value of reference on the stability analysis of landslide mass under the similar engineering geological conditions.

Keywords. Three Gorges Reservoir; landslide mass; deformation characteristics; stability mechanisms; the field monitoring.

\section{Introduction}

Completed in 2009, the Three Gorges Dam in China is the world's largest hydroelectric project, generating as much as $9.8 \mathrm{kWh}$ of electrical power every single day. The dam is $185 \mathrm{~m}$ high, 2.3 $\mathrm{km}$ long and its normal water level fluctuates between 145 and $175 \mathrm{~m}$. Although the Three Gorges Dam will eventually provide the huge hydropower resources and mitigate the devastating effects of flooding, the frequency of geological disasters is greatly increased due to the large increase and the subsequent decline in water level (Wang et al. 2005b; He et al. 2008; Yan and Wang 2010; Du et al. 2013; Wang and Qiao 2013; Tang et al. 2014; Zhang et al. 2015).

In June 2003, the reservoir water level rose to $135 \mathrm{~m}$ from the original minimum level firstly, which caused the occurrence of some landslides. For example, the Qianjiangping landslide occurred in Shazhenxi town at the bank of Qinggan-he River, a tributary of the Yangtze River (figure 1) on 14 July 2003 (Wang et al. 2004; Zhang et al. 2004). There were no casualties due to the local 


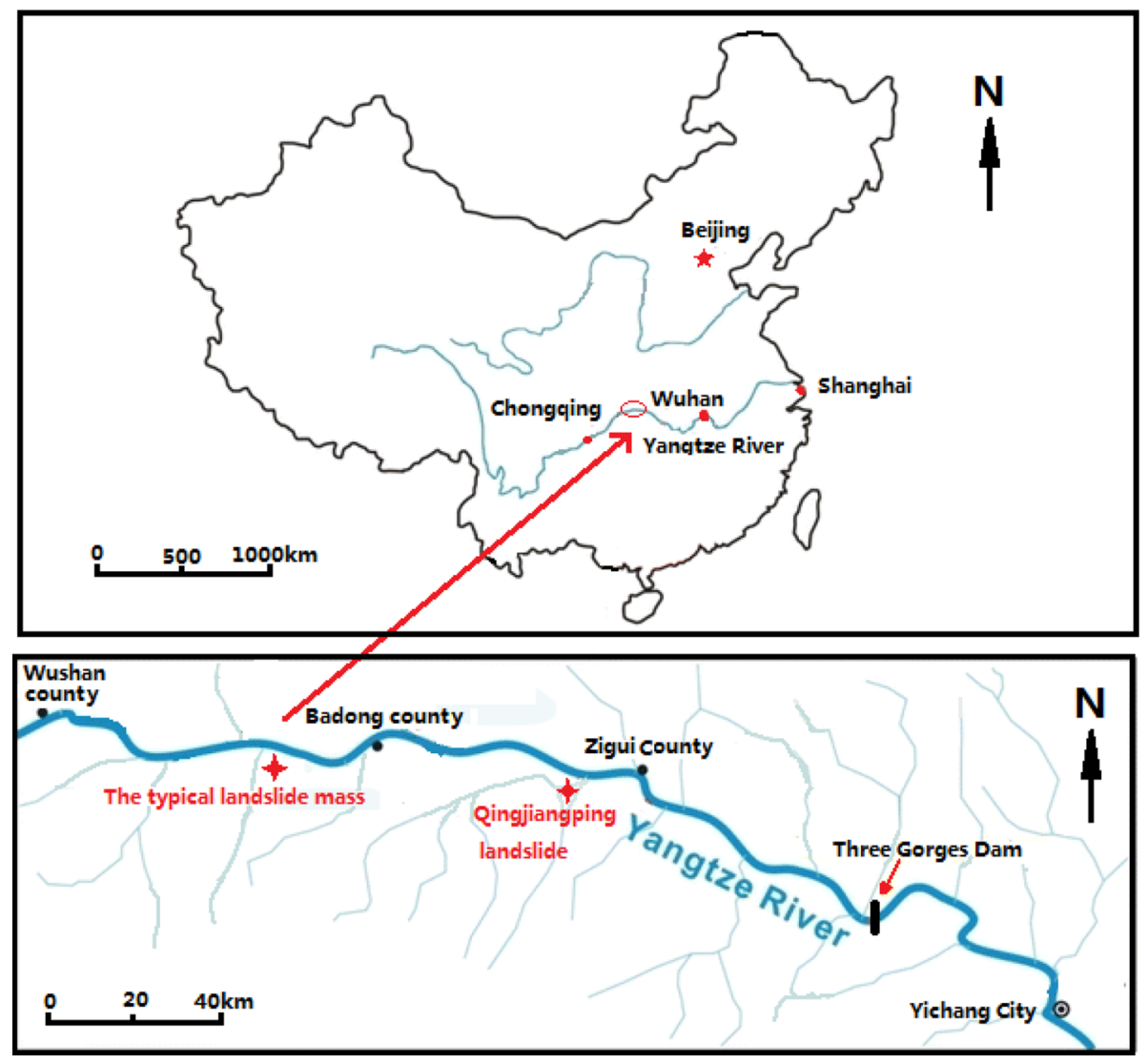

Figure 1. Location map of the landslide mass in the central region of China.

government's timely warning and the evacuation. However, residents' homes were damaged. According to statistics, Shazhenxi town lost about $40 \%$ of its total assets because of this disaster (Wang et al. 2005a; Yin and Peng 2007). On 20 September 2006, the reservoir began to impound again, and the water level has risen from 135 to $156 \mathrm{~m}$ in $38 \mathrm{~d}$. The deformation of landslide mass became more serious because of the fluctuation of the water level. The deformation of a large number of landslides accelerated in July 2007 after the drawdown of the water level from 156 to $145 \mathrm{~m}$ (Yan and Wang 2010; Wang and Qiao 2013; Tang et al. 2014).

Therefore, there is an urgent need to study the deformation characteristics and instability mechanisms of a landslide in the Three Gorges Reservoir region, as these are important factors in the prediction, evaluation and prevention of the reservoir landslides.

Field investigations (Ocakoglu et al. 2002, 2009; Gokceoglu et al. 2005; Pradhan et al. 2010; Hu et al. 2015) and numerical simulations (Alemdag et al. 2014; Longoni et al. 2014; Zhang et al. 2017) are widely used to study the deformation and stability mechanisms of landslide mass. Moreover, the field monitoring of the surface displacement has also been applied by some researchers (Lee 2004; Panizzo et al. 2005; Su et al. 2009; Fan et al. 2010; Zhang et al. 2010; Mazaeva et al. 2013; Tang et al. 2015; Xia et al. 2015; Renato et al. 2016). However, the recent studies have paid little attention to applying an integrated monitoring system to a single landslide. Such as a system monitors surface displacement, internal displacement and precipitation.

In this paper, a typical landslide mass in the Three Gorges Reservoir region is taken as an example. Through the deep excavation and analysis based on a large number of monitoring data from the landslide mass incorporating the GPS monitoring of surface deformation, the inclinometer monitoring of internal deformation, precipitation and the variation of the reservoir water level in past over 7 yrs, the deformation characteristics and the stability mechanisms of landslide mass are discussed. 


\section{Engineering geological environment of the landslide region}

The landslide mass in the study is situated on the right bank of the Yangtze River, in Badong County, Hubei Province. The planar shape of the landslide mass approximates a triangle of length $460 \mathrm{~m}$ and width $360 \mathrm{~m}$. The average thickness of the sliding mass is about $20-30 \mathrm{~m}$, and the landslide has an area of $16.6 \times 10^{4} \mathrm{~m}^{2}$ and an estimated volume of $447 \times 10^{4} \mathrm{~m}^{3}$. The sliding direction of landslide mass is $332^{\circ} \mathrm{N}$, which is approximately

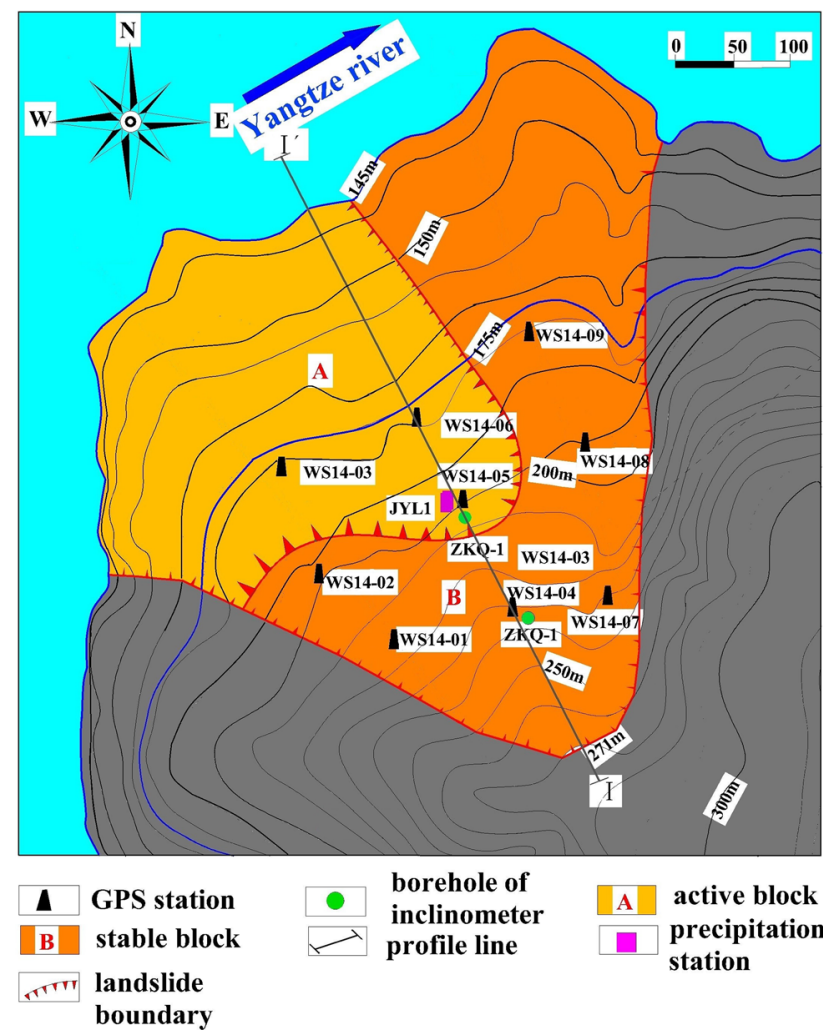

Figure 2. Geomorphological map of the research site, showing the monitoring network. perpendicular to the Yangtze River. The vertical height of the landslide is $132 \mathrm{~m}$, and its elevation ranges from 138 to $270 \mathrm{~m}$. The average slope angle is about $20^{\circ}$. The left side and right side are bounded by the gully, and the trailing edge is bounded by the steep wall. Also, the front edge and trailing edge are steep, and the middle part of landslide mass is relatively slow. In addition, the deformation of A block of landslide mass is strong and the deformation of $\mathrm{B}$ block is relatively weak (figure 2).

The geological units and structure of the landslide mass were analysed based on the information which was obtained from field investigations and exploration. The landslide mass consists of the residual silty clay soil with about $35 \%$ gravel. The bedrock mainly consists of the green-gray marlite of the thin layer, the interbedded dolomitic limestone and the purple-red mudstone of the Badong Formation from the Triassic. The strength of marble and mudstone is low with a weak interlayer between them. The dip direction of the bedding plane is $286^{\circ}$, which is similar to the dip direction of the landslide mass and the sliding direction of the landslide mass. The dip angle of the bedding plane is $10^{\circ}$. The stratum of the Badong Formation is called one of the 'easiest sliding strata' (which means that landslides occur most frequently in these strata) in China due to its special geological setting and low strength (figure 3 ).

\section{Analysis of the deformation characteristics of the landslide mass}

\subsection{The surface deformation characteristics}

Since the reservoir water level of the Three Gorges Reservoir region reached $135 \mathrm{~m}$ in 2003, the

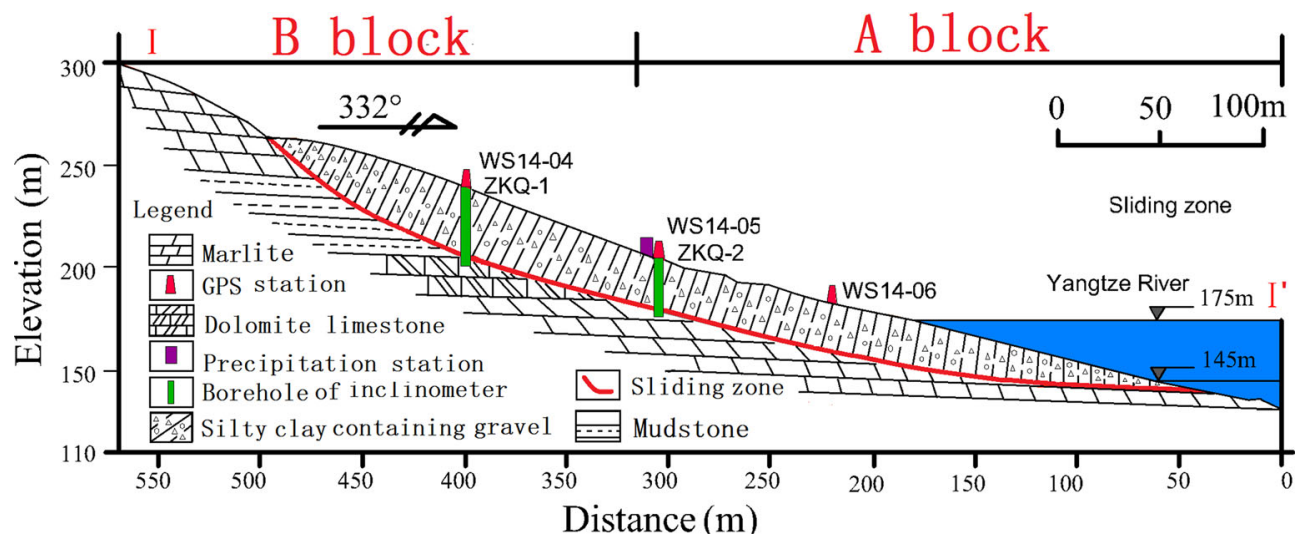

Figure 3. Section map along the I-I' profile of the typical landslide mass. 

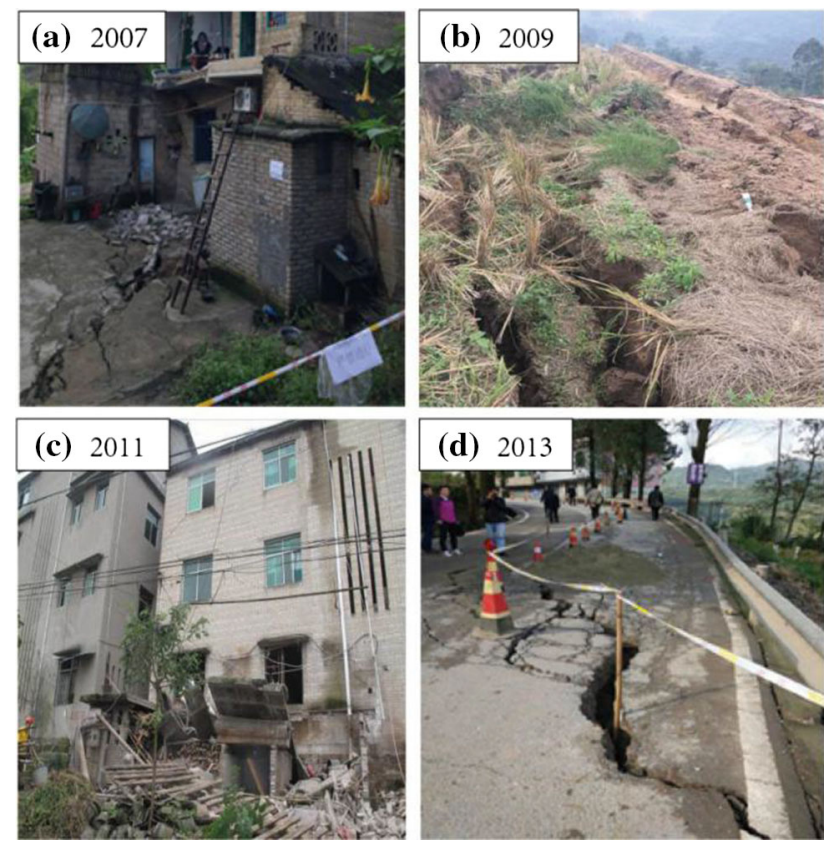

Figure 4. Surface deformation characteristics.

landslide has been in a creeping deformation state. Especially, after 2006, the landslide mass greatly deformed every year with the periodic fluctuation of the water level, showing the stepped deformation characteristic. In 2007, there was a large deformation that a number of tensile cracks appeared and the houses also cracked on the landslide mass in May-July (figure 4a). A larger deformation occurred in the trailing edge of the landslide mass with a large amount of tensile cracks after water impoundment of the reservoir in 2009, and the largest crack has a drop of $33 \mathrm{~cm}$ and the maximum width of crack is $26 \mathrm{~cm}$. Furthermore, the landslide mass is always in a stage of the continuous deformation (figure $4 \mathrm{~b}$ ). The surface cracks continued to increase after 2011 (figure 4c and d).

\subsection{The analysis of the monitoring data}

The landslide mass began to implement the professional monitoring incorporating GPS monitoring of surface deformation and inclinometer monitoring of internal deformation, and the monitoring frequency is 1 time/month. It is based on the monitoring data of 82 months from January 2007 to December 2013 to the analysis in this paper.

\subsubsection{GPS monitoring of surface deformation}

There are nine GPS monitoring stations on the landslide mass including the surface deformation monitoring stations of WS14-01-WS14-09. The distribution of the monitoring stations is shown in figure 2. It is revealed that the landslide mass appears as a stepped deformation characteristic, which mainly occurs in A block since the implementation of the professional monitoring in 2007 by the cumulative displacement curve of the monitoring points of the landslide mass (figure 5). The displacement of nine GPS surface monitoring points is synchronous, but their range of variety is obvious. Similarly, the surface cumulative displacement curve suddenly rises in May-July each year, but remains stable from September to April of the following year. Especially, in 2007, 2009 and 2011, the increase of the displacement of the landslide mass is intense. For example, the displacement of WS14-06 monitoring point increased to $650 \mathrm{~mm}$ dramatically in May and June 2011. The displacement rate curves in 2007, 2009 and 2011, as shown in figure 6 , have the law of fluctuation that the displacement rate of GPS monitoring points of surface deformation was in wave crest in May and June each year, and then gradually come down. For example, the maximum displacement rate reached $27.2 \mathrm{~mm} / \mathrm{d}$ in A block of the landslide mass on 15 June 2011.

In addition, according to the results shown in figure 5, we deduced that the displacement of WS14-03, WS14-05 and WS14-06 was large and increased year by year, and the displacement of WS14-06 > WS14-05 > WS14-03, while the increase of the displacement of the other monitoring points is relatively small in the whole monitoring process. The above results show that the displacement of A block of the landslide mass is larger than that of B block, and the deformation of the landslide mass has the characteristic of the tractive sliding.

It is reflected in figure $7(\mathrm{a})$ that the annual average displacement rate of WS14-06, WS14-03 and WS14-05 is much bigger than the other monitoring points, the average displacement rate of WS14-06, WS14-03 and WS14-05 fluctuated between 0.66 and $2.97 \mathrm{~mm} / \mathrm{d}$, and the other monitoring points were under $0.65 \mathrm{~mm} / \mathrm{d}$. Especially, in 2007, 2009 and 2011, the annual average displacement rate increased obviously and reached the historical maximum in 2011. In addition, it is shown in figure $7(\mathrm{~b})$ that the maximum displacement rate of monitoring points mainly appeared in 2009 and 2011, respectively, reached 17.48 and $27.21 \mathrm{~mm} / \mathrm{d}$. Through the analysis of figures 8 and 9 , it is discovered that the water level of the Three Gorges 


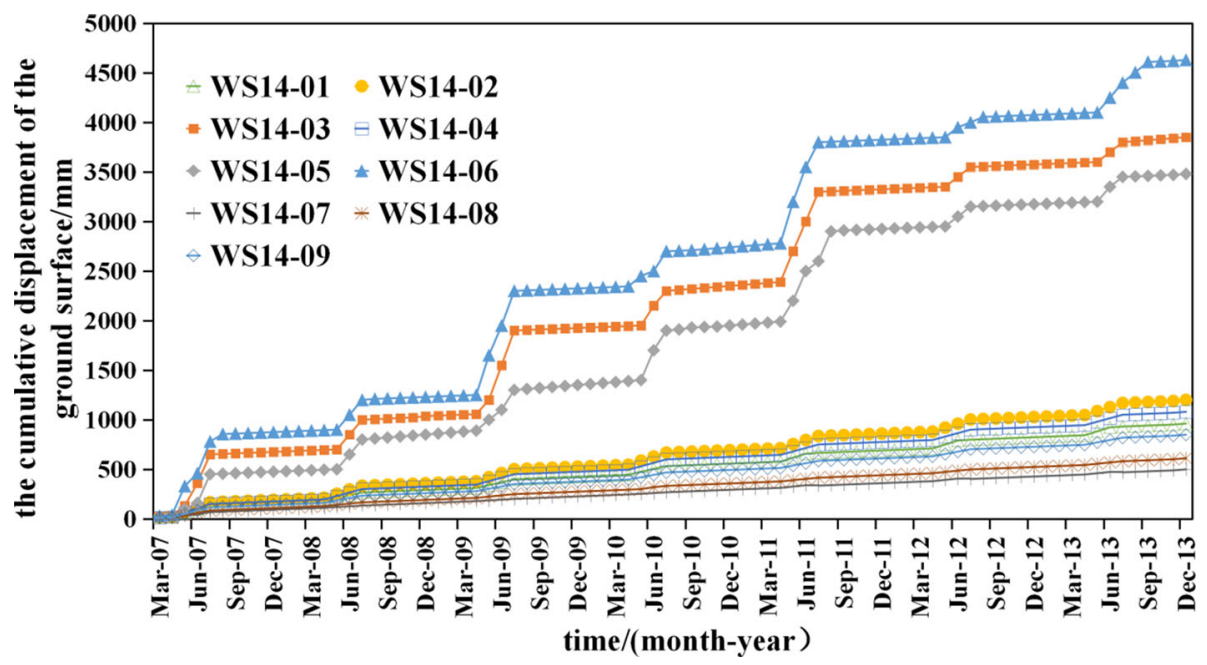

Figure 5. Surface accumulative displacement curve of landslide mass.

Reservoir region began to fall firstly from 175 to $145 \mathrm{~m}$ in 2009, the drawdown rate of the reservoir water level was fast to reach $0.28 \mathrm{~m} / \mathrm{d}$, and the precipitation also was high to reach $204.9 \mathrm{~mm}$ in June. In addition, starting from May 2011, the drawdown rate of the reservoir water level was fast, and its average drawdown rate was to reach 0.35 $\mathrm{m} / \mathrm{d}$, which even reached $0.41 \mathrm{~m} / \mathrm{d}$ especially from 1 to 10 June. Moreover, the precipitation was also up to $220 \mathrm{~mm}$. This is the reason why the displacement rate of landslide mass reached the maximum with the rapid drawdown of the reservoir water level and the heavy rainfall.

\subsubsection{Analysis of inclinometer monitoring of internal deformation}

There are two inclinometers to monitor the internal deformation of the landslide mass (figure 1). It is indicated by inclinometer ZKQ1 that the depth of the sliding zone is about 36 $\mathrm{m}$ and the maximum of the internal accumulative displacement is $25 \mathrm{~mm}$, which illustrates that the internal deformation of the trailing edge of the landslide mass has a slight sliding (figure 10a). Meanwhile, it is shown by inclinometer ZKQ-2 that the depth of the sliding zone is about $10-12 \mathrm{~m}$, and its average accumulative displacement is 48 $\mathrm{mm}$. The displacement has an increasing tendency as a whole when the depth is above $6 \mathrm{~m}$, and the maximum displacement reaches $72 \mathrm{~mm} /$ month (figure 10b). By comparison of two inclinometers, it can be seen that the whole displacement of the inclinometer ZKQ-2 is much larger than that of the inclinometer ZKQ-1, which explains the displacement of the middle and lower of the landslide mass is less than that of the upper in the profile I-I'.

Through the comprehensive analysis of the surface and internal deformation monitoring results, it is indicated that the deformation of $\mathrm{A}$ block of landslide mass is strong and B block is weak relatively, the landslide mass is always in the creeping stage, the surface and internal displacement curves possess synchronisation and the surface displacement is greater than the internal displacement in the profile $\mathrm{I}^{\prime} \mathrm{I}^{\prime}$.

\section{The analysis of the factors of the deformation characteristics and the stability mechanisms of the landslide mass}

The special topography, lithology and geological structure of landslide are the essential factors of landslide formation and control the formation and development of landslide. In addition, the fluctuation of the water level of the Three Gorges Reservoir region induces the growth of landslide mass and the rainfall accelerates the deformation of the landslide mass. These factors play an important role in the deformation of the landslide mass.

\subsection{The control of geological factors on the deformation of the landslide mass}

There is a possibility of the landslide if there is a slope. The landslide mass in the study is situated on a slope of the right bank of the Yangtze River. Its front edge and the trailing edge are steep, the 


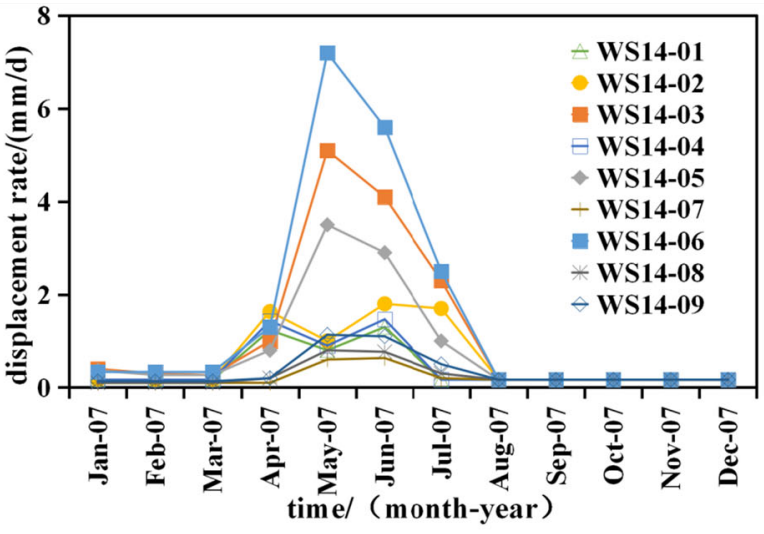

(a) 2007

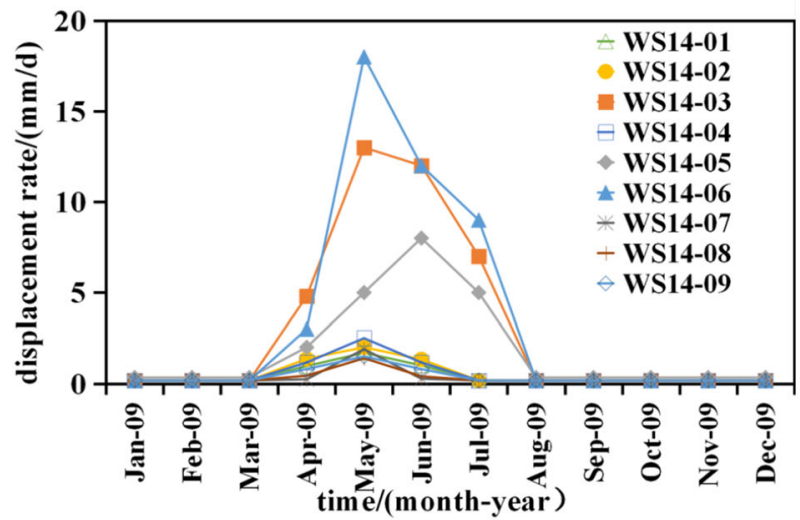

(b) 2009

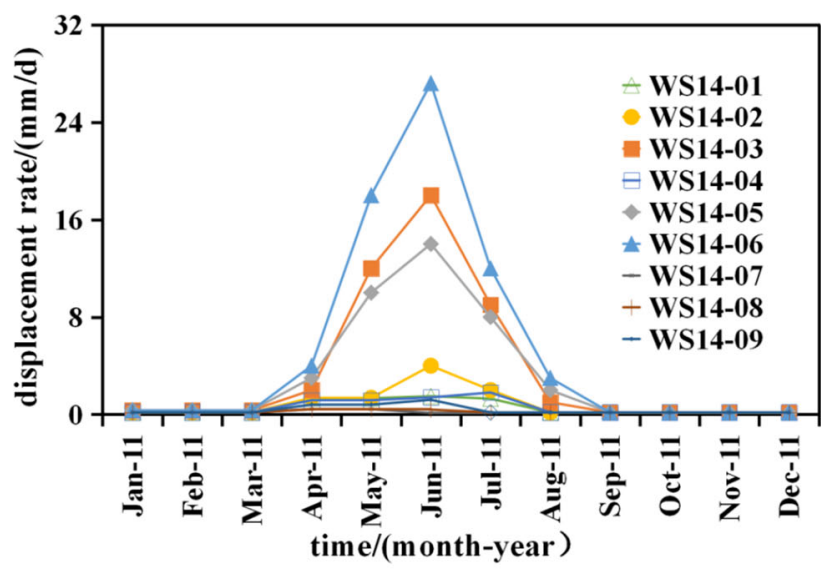

(c) 2011

Figure 6. Displacement rate of landslide mass in 2007, 2009 and 2011.

middle part is slow and the average slope angle is about $20^{\circ}$. The planar shape of the landslide mass approximates a triangle, the left side and right side are bounded by the gully, and the trailing edge is bounded by the steep wall, which indicates that the free surface conditions of the slope are better. These terrain conditions are conducive to the formation and development of the landslide mass.

The occurrence of the landslide is mainly controlled by the slippery stratum, such as

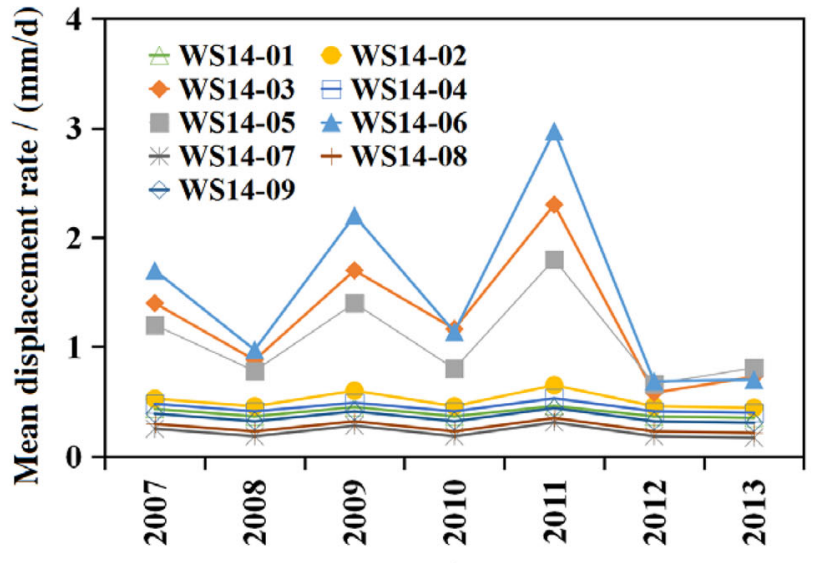

Time / years

(a) Annual mean displacement rate

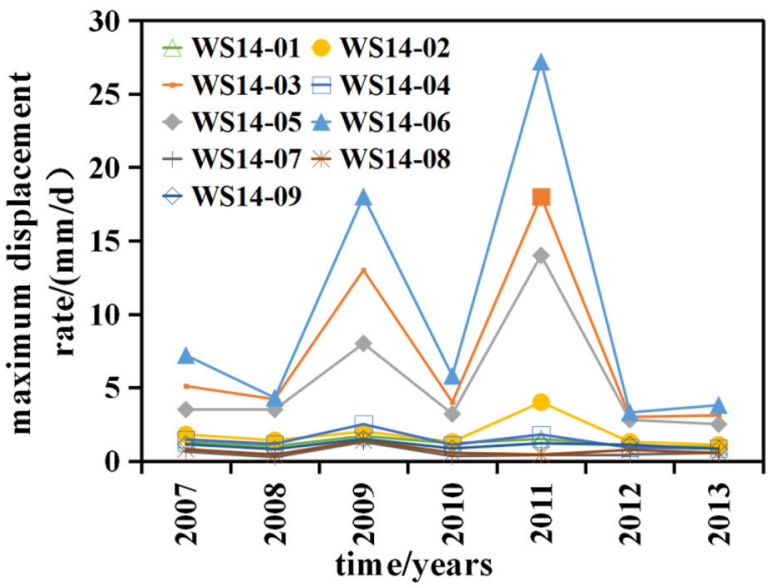

(b) Annual maximum displacement rate

Figure 7. Curves of annual mean displacement rate and annual maximum displacement rate.

layered strata containing the plane of weakness and the weak intercalation (zone). The landslide mass develops in the stratum of the Badong Formation of the Three Gorges Reservoir that is called one of the 'easiest sliding strata' (which means that landslides occur most frequently in these strata) in China due to its special geological setting and low strength (figure 3 ). The weak stratum in the landslide region lays the material foundation for the deformation and failure of the landslide mass. The weak intercalation at the lower part of the landslide mass causes the creep deformation under the force of gravity, which pulls the upper rock-soil mass to generate the tensile deformation, and gradually develops into the large-scale sliding deformation.

In addition, the cracks are developed due to the influence of regional structure, the cracks of the dip direction NNW and NWW are developed particularly and their occurrence is almost concordant with the slope direction, which provides a 


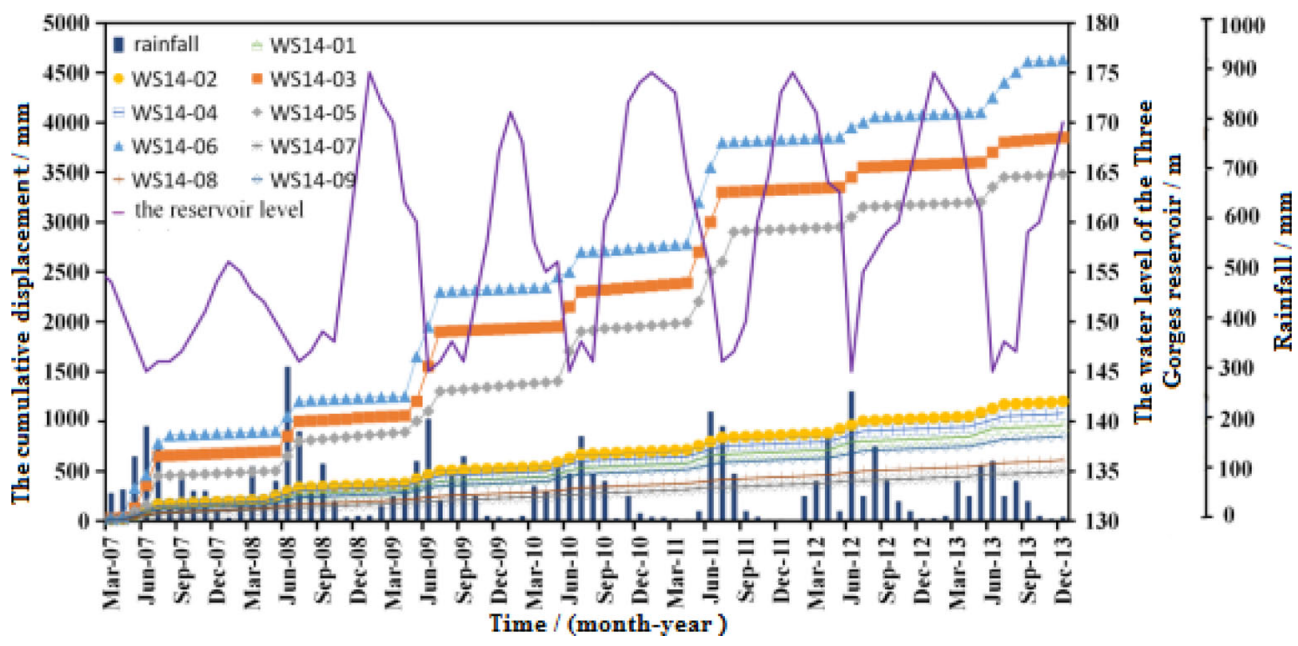

Figure 8. Accumulative displacement of landslide mass-water level-rainfall-time.

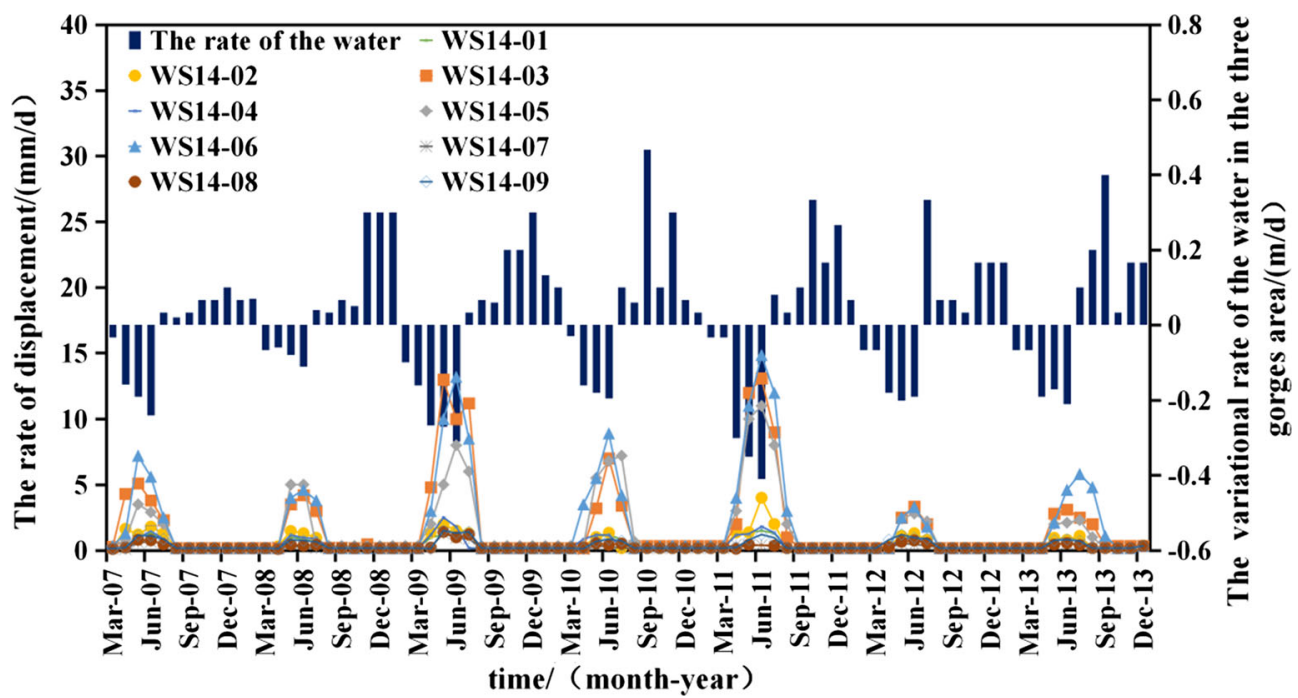

Figure 9. The relation between displacement rate of landslide mass and variational rate of reservoir water level.

cutting surface for the formation of the landslide mass. It is advantageous to form the bottom sliding surface that the gently inclined structural plane is inclined to the outside of the landslide mass.

\subsection{Influence of the rainfall on the deformation of the landslide mass}

The rainfall has a great influence on the deformation of the landslide mass. The rainfall infiltrates into the landslide mass, which increases the self-weight of the landslide mass and forms the seepage pore pressure to make the soil of the sliding zone soft and decreases the mechanical parameters. It is shown by the relationship between the surface accumulative displacement of the landslide mass and precipitation that both of them have a significant correlation (figure 8). The surface accumulative displacement curve has an appearance of a step during the annual concentrated period of the rainfall. Moreover, the period of the annual concentrated rainfall is consistent with the intense increase of the surface accumulative displacement curve, which indicates adequately that the rainfall is one of the factors of the deformation of the landslide mass. From the analysis of figure 8, however, we can find that the average precipitation in April-September 2008 was much larger than that in 2007 and 2009, while the increment of the surface cumulative displacement in AprilSeptember 2008 was smaller than that in 2007 and 2009. Furthermore, it is indicated by figure 9 that the average drawdown rate of the reservoir water level was maintained at $0.2 \mathrm{~m} / \mathrm{d}$ in May 
(a) The cumulative displacement $/ \mathrm{mm}$

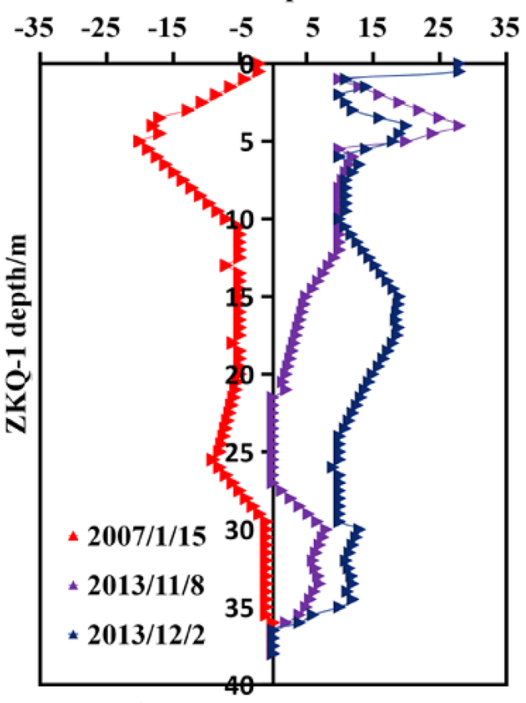

(b) The cumulative displacement $/ \mathrm{mm}$

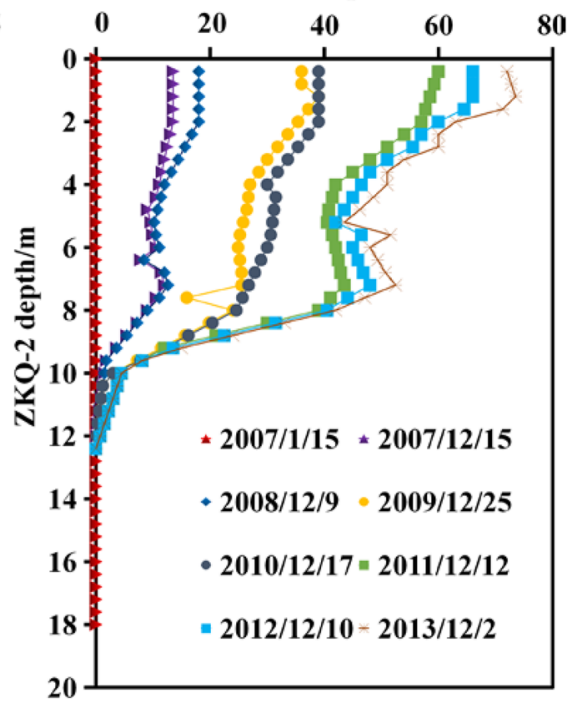

Figure 10. Internal displacement monitoring curve of landslide mass.

2012 and 2013, while the incremental of the surface cumulative displacement of WS14-06 in 2012 was less than that in 2012 when the rainfall in 2012 was more than that in 2013.

\subsection{Influence of the fluctuation of the reservoir water level on the deformation of the landslide mass}

It is shown by the relationship between the surface accumulative displacement of the landslide mass and the fluctuation of the reservoir water level that both of them have an important correlation (figure 8). The surface accumulative displacement curve has a palpable stepped increment in JuneSeptember each year, which indicates that the displacement of all monitoring points causes changes. And at this time, the water level of the Three Gorges Reservoir region was dropping rapidly or running at the low water level. However, the surface accumulative displacement curve is relatively stable during the annual October-March of the flowing year, which indicates that the displacement of the monitoring points has a very small change. And at this time, the water level of the Three Gorges Reservoir region was rising or running at the high water level. The drawdown of the water level of the Three Gorges Reservoir region is the main controlling factor of the deformation of the landslide mass through the comparison of the above facts, while the raise of the reservoir water level has little effect on the deformation of the landslide mass. This is the reason why the surface accumulative displacement curve of the landslide mass has a typical stepwise deformation characteristic and shows the seven corresponding steps.

Figure 9 shows the relationship between the rate of displacement of the landslide mass and the variational rate of the water level of the Three Gorges Reservoir region. The reservoir water level fluctuated between 145 and $156 \mathrm{~m}$ in 2007 and 2008 , the average drawdown rate of the water reservoir level was $0.20 \mathrm{~m} / \mathrm{d}$ in May and June 2007, which was larger than $0.08 \mathrm{~m} / \mathrm{d}$ in May and June 2008. Accordingly, the average displacement rate and the amount of surface displacement of the landslide mass in 2007 are larger than that in 2008 during this period. The reservoir water level fluctuated between 145 and $175 \mathrm{~m}$ in 2009 to 2013, the average drawdown rate of the water reservoir level was $0.28 \mathrm{~m} / \mathrm{d}$ and $0.35 \mathrm{~m} / \mathrm{d}$ in May and June 2009 and 2011, which was larger than 0.18, 0.2 and $0.19 \mathrm{~m} / \mathrm{d}$ in 2010, 2012 and 2013, respectively. Correspondingly, the average displacement rate and the amount of surface displacement of the landslide mass in 2009 and 2011 are larger than that in 2010, 2012 and 2013 during this period. It can be seen that the drawdown rate of the reservoir water level has a great influence on the deformation of the landslide mass, and the deformation becomes intense as the drawdown rate of the landslide mass becomes faster. Also, the landslide mass is a typical landslide induced by the drawdown of the reservoir water level. 


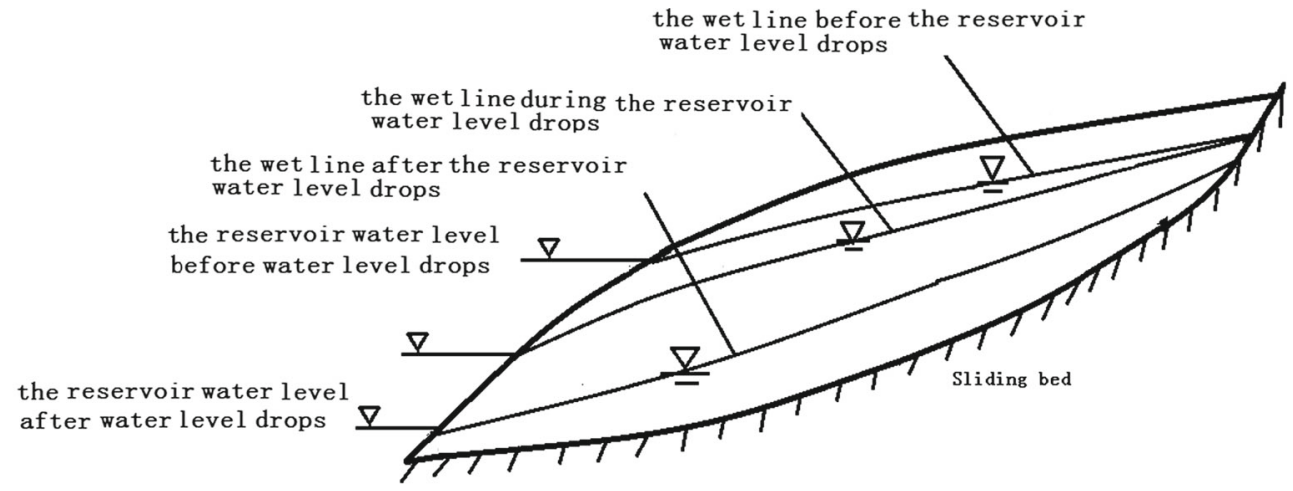

Figure 11. Diagram of groundwater seepage mode of landslide induced by the drawdown of the reservoir water level.

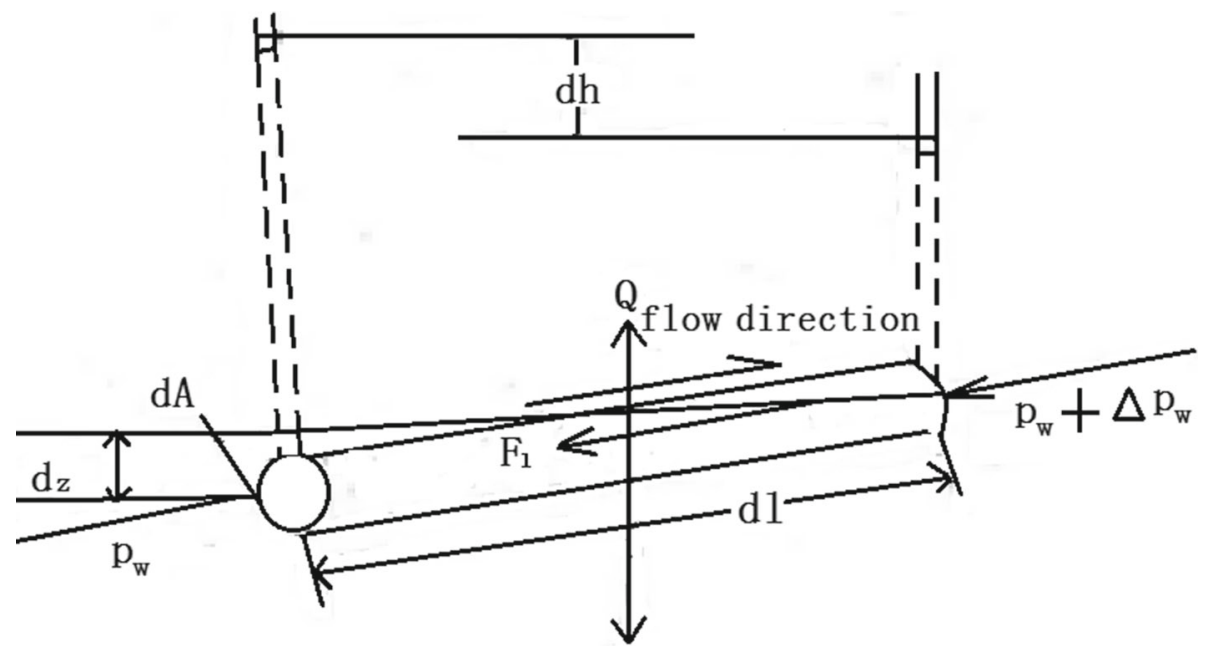

Figure 12. Force diagram on soil micro element in the seepage field.

\subsection{Research of the deformation characteristics and instability mechanisms of the landslide mass}

According to the analysis of the above results, the drawdown of the reservoir water level has a great influence on the deformation of the landslide mass, and the deformation becomes intense as the drawdown rate of the reservoir water level becomes faster. So the landslide mass is a typical landslide induced by the drawdown of the reservoir water level, and it is necessary to study the deformation characteristics and instability mechanisms of the landslide mass.

The groundwater of the landslide mass declines with the drawdown of the reservoir water level. However, if the permeability of the rock and soil mass of the landslide is poor and the groundwater cannot be discharged immediately, the groundwater recession will lag behind the drawdown of the reservoir water level. At this time, the saturation line of the groundwater has a steep bending near the outside of the landslide mass and has a shape of the gentle slope near the inside of the landslide mass (figure 11). In addition, the drawdown rate of the landslide mass is faster and the permeability of the rock and soil mass is slower, which result in the groundwater recession rate to be slower, the saturation line of the groundwater is steeper near the outside of the landslide mass and the effective head between the reservoir water level and the groundwater becomes larger, as a result of which the groundwater of the landslide mass is discharged outward and the direction of the generating seepage pressure points to the outside of the landslide mass. Especially, in the process of the rapid drawdown of the reservoir water level, the generated seepage pressure is harmful to the stability of the landslide mass.

In the following, a simplified mechanical model is established to quantitatively calculate the seepage pressure, which further explains the seepage effect 
on the drawdown of the reservoir water level to the soil. $\mathrm{d} l$ is used to express the length of a streamline direction in a seepage field and $\mathrm{d} A$ is used to express the area of the transverse section of the corresponding section (figure 12).

(1) Assuming that the seepage direction is normal, a difference of pore water pressure on both sides of the soil column is

$$
\Delta P_{\mathrm{w}}=-\mathrm{d} p_{\mathrm{w}} \mathrm{d} A=p_{\mathrm{w}} g(-\mathrm{d} h+\mathrm{d} z) \mathrm{d} A .
$$

(2) Projecting the self-weight of the flow in the soil column towards the streamline direction to obtain its component of force:

$$
W=-n p_{\mathrm{w}} g \mathrm{~d} A \mathrm{~d} l \frac{\mathrm{d} z}{\mathrm{~d} l} .
$$

(3) The total frictional resistance of the skeleton to the flow of the pore:

$$
F_{l}=f_{l} \mathrm{~d} A \mathrm{~d} l .
$$

(4) Projecting the buoyancy of the soil particles affected by water towards the streamline direction to obtain its component of force:

$$
Q=-(1-n) p_{\mathrm{w}} g \mathrm{~d} A \mathrm{~d} l \frac{\mathrm{d} z}{\mathrm{~d} l},
$$

where $p_{\mathrm{w}}$ is the density of water, $n$ the porosity and $g$ the acceleration due to gravity.

Here, ignoring the seepage inertia force to establish the balance equations of the four forces above, we get

$$
f_{l}=p_{\mathrm{w}} g \frac{\mathrm{d} h}{\mathrm{~d} l} .
$$

There are acting force and counteracting force between the seepage and the skeleton of the soil and the direction of the seepage force on the soil particles is the same as the direction of the flow. So, the expression of the seepage pressure of the soil is

$$
f=-f_{l}=-p_{\mathrm{w}} g \frac{\mathrm{d} h}{\mathrm{~d} l}=p_{\mathrm{w}} g I .
$$

$I=-\mathrm{d} h / \mathrm{d} l$ represents the hydraulic gradient in the formula. The seepage pressure is directly dependent on the hydraulic gradient due to $p_{\mathrm{w}}$ and $g$ is the definite value. The seepage pressure originates from the pore water pressure, acting on the soil particles in the range of the seepage, which is the process that the external force translates into the evenly distributed body force.
The substance of the landslide mass is the silty clay containing gravel with the poor permeability. When the drawdown rate of the reservoir water level is large, the groundwater drains into the reservoir. Because the permeability of the landslide mass is poor, the groundwater forms the hysteresis effect and the huge hydraulic gradient is formed, which cause the drastic increase of the seepage pressure of the landslide mass and destroy the original balance. Thereby, the stability of the landslide mass decreases significantly and its deformation intensifies.

\section{Conclusions}

- According to the analysis of GPS surface monitoring of deformation of the landslide, the displacement of WS14-03, WS14-05 and WS1406 was large and increased year by year, while the increase of the displacement of the other monitoring points is relatively small in the whole monitoring process, which has the characteristic of the tractive sliding.

- In contrast to the analysis results of inclinometer monitoring of the internal deformation, the surface displacement is greater than the internal displacement. The maximum of the internal accumulative displacement of inclinometer ZKQ1 is $25 \mathrm{~mm}$. And the average accumulative displacement of inclinometer ZKQ-2 is $480 \mathrm{~mm}$ and its displacement has an increasing tendency as a whole when the depth is above $6 \mathrm{~m}$.

- Discussing the deformation mechanism of the landslide, we find that the drawdown of the water level of the Three Gorges Reservoir region is the main controlling factor of the deformation of the landslide mass.

\section{Acknowledgements}

This research was supported by the Fundamental Research Funds for the Central Universities (No. 2015XKMS035), and the Priority Academic Program Development of Jiangsu Higher Education Institutions (PAPD) and the National Natural Science Foundation of China (Nos. 41602294, 41602310).

\section{References}

Alemdag S, Akgün A, Kaya A and Gokceoglu C 2014 A large and rapid planar failure: Causes, mechanism and 
consequences (Mordut, Gumushane, Turkey); Arab J. Geosci. 7 1205-1221.

Du J, Yin K and Lacasse S 2013 Displacement prediction in colluvial landslides, Three Gorges Reservoir, China; Landslide 10 203-218.

Fan H G, Liu Q Q and An Y 2010 Effects of fracture seepage on the stability of landslide during reservoir water level fluctuation; Disaster Adv. 3 306-308.

Gokceoglu C, Sonmez H, Nefeslioglu H A, Duman T Y and Can T 2005 The 17 March 2005 Kuzulu landslide (Sivas, Turkey) and landslide-susceptibility map of its near vicinity; Eng. Geol. 81 65-83.

He K Q, Li X R and Yan X Q 2008 The landslides in the Three Gorges Reservoir region, China and the effects of water storage and rain on their stability; Env. Geol. 55 $55-63$.

Hu X L, Zhang M, Sun M J, Huang K X and Song Y J 2015 Deformation characteristics and failure mode of the Zhujiadian landslide in the Three Gorges Reservoir, China; Bull. Eng. Geol. Environ. 74 1-12.

Lee C 2004 Landslide potentiality of the Tsengwen Reservoir watershed, Taiwan, China; Int. J. Sedim. Res. 19 123-129.

Longoni L, Papini M, Arosio D, Zanzi L and Brambilla D 2014 A new geological model for Spriana landslide; Bull. Eng. Geol. Environ. 73 959-970.

Mazaeva O, Khak V and Kozyreva E 2013 Model of erosionlandslide interaction in the context of reservoir water level variations (East Siberia, Russia): Factors, environment and mechanisms; J. Earth Syst. Sci. 122 1515-1531.

Ocakoglu F, Gokceoglu C and Ercanoglu M 2002 Dynamics of a complex mass movement triggered by heavy rainfall: A case study from NW Turkey; Geomorphology 42329 341.

Ocakoglu F, Acikalin S, Gokceoglu C, Karabacak V and Cherkinsky A 2009 A multistory gigantic subaerial debris flow in an active fault scarp in NW Anatolia, Turkey: Anatomy, mechanism and timing; Holocene 19 955-965.

Panizzo A, Girolamo P D, Risio M D, Maistri A and Petaccia A 2005 Great landslide events in Italian artificial reservoir; Nat. Hazards Earth Syst. Sci. 5 733-740.

Pradhan B, Sezer E A, Gokceoglu C and Buchroithner M F 2010 Landslide susceptibility mapping by neuro-fuzzy approach in a landslide-prone area (Cameron Highlands, Malaysia); IEEE Trans. Geosci. Remote Sens. 48 41644177.

Renato M, Michael H and Martin C D 2016 Developing an early warning system for a very slow landslide based on displacement monitoring; Nat. Hazards 81 887-907.

Su M B, Chen I H and Liao C H 2009 Using TDR cables and GPS for landslide monitoring in high mountain area; J. Geotech. Geoenviron. Eng. 135 1113-1121.
Tang H M, Li C D, Hu X L, Su A J, Wang L Q, Wu Y P, Robert C, Xiong C R and Li Y N 2014 Evolution characteristics of the Huangtupo landslide based on in situ tunneling and monitoring; Landslides 12 511-521.

Tang H M, Li C D, Hu X L, Wang L Q, Criss R, Su A J, Wu Y P and Xiong C R 2015 Deformation response of the Huangtupo landslide to rainfall and the changing levels of the Three Gorges Reservoir; Bull. Eng. Geol. Environ. 74 933-942.

Wang M and Qiao J P 2013 Reservoir-landslide hazard assessment based on GIS: A case study in Wanzhou section of the Three Gorges Reservoir; J. Mt. Sci. 10 1085-1096.

Wang $\mathrm{F} \mathrm{W}$, Zhang $\mathrm{Y}$ M, Huo Z T, Matsumoto $\mathrm{T}$ and Huang B L 2004 The July 14, 2003 Qianjiangping landslide, Three Gorges Reservoir, China; Landslide 1 157162.

Wang F W, Wang G H, Sassa K, Takeuchi A, Araiba K, Zhang Y M and Peng X M 2005a Displacement monitoring and physical exploration on the Shuping landslide reactivated by impoundment of the Three Gorges Reservoir, China; In: Landslides, Springer, Berlin, Heidelberg, pp. 313-319.

Wang F, Wang G, Sassa K, Araiba K, Takeuchi A, Zhang Y, Huo Z, Peng X and Jin W 2005b Deformation monitoring and exploration on Shuping landslide induced by impoundment of the Three Gorges Reservoir, China; Ann. Dis. Prev. Res. Inst. Kyoto Univ. 48 405-412.

Xia M, Ren G M, Zhu S S and Ma X L 2015 Relationship between landslide stability and reservoir water level variation; Bull. Eng. Geol. Environ. 74 909-917.

Yan Z L and Wang J J 2010 Influence of water level fluctuation on phreatic line in silty soil model slope; Eng. Geol. 113 90-98.

Yin Y and Peng X 2007 Failure mechanism on Qianjiangping landslide in the Three Gorges Reservoir region; Hydrogeol. Eng. Geol. 3 51-54.

Zhang Y M, Liu G R, Chang H, Huang B L and Pan W 2004 Tectonic analysis on the Qianjiangping landslide in three Gorges reservoir area and a revelation; Yangtze River 35 $24-26$.

Zhang T, Yan E, Cheng J and Zheng Y 2010 Mechanism of reservoir water in the deformation of Hefeng landslide; J. Earth Sci. 6 870-875.

Zhang G C, Xie N, Tang H M, Zhang L and Wu J P 2015 Survey and cause analyses of ground surface deformation near a foundation pit slope: A case study in the three Gorges area, China; Nat. Hazards 75 13-31.

Zhang T W, Cai Q X, Han L, Shu J S and Zhou W 2017 3D stability analysis method of concave slope based on the Bishopmethod; Int. J. Mining Sci. Technol. 27 365-370. 